\title{
Impact of HbA1c criterion on the definition of glycemic component of the metabolic syndrome: the China health and nutrition survey 2009
}

\author{
Xingxing Sun ${ }^{1+}$, Tingting $\mathrm{Du}^{2+}$, Rui Huo ${ }^{2}$, Xuefeng $\mathrm{Yu}^{2^{*}}$ and Lixian $\mathrm{Xu}^{{ }^{*}}$
}

\begin{abstract}
Background: In 2009, a unified definition of metabolic syndrome (MetS) was proposed, of which, the glycemic component is defined on the basis of fasting plasma glucose (FPG) level. Recently, the American Diabetes Association (ADA) recommended the use of glycated hemoglobin ( $\mathrm{HbA1c}$ ) as an alternative to FPG to define prediabetes. Hence, we aim to compare the performance of HbA1c and FPG in the definition of glycemic component of the MetS among Chinese adults.
\end{abstract}

Methods: We conducted a cross-sectional analysis of 7641 Chinese participants aged $\geq 18$ years using data from the China Health and Nutrition Survey 2009. MetS was defined according to the consensus criteria in 2009. We compared the use of $\mathrm{HbA} 1 \mathrm{c}$ versus FPG in the definition of the glycemic component of MetS. Increased HbA1c value was defined following the criterion of HbA1c cut-off point of $\geq 5.7 \%$ recommended by the ADA.

Results: Overall, 1136 (14.9\%) had MetS according to FPG $\geq 5.6 \mathrm{mmol} / \mathrm{l}$, and 1640 (21.5\%) had MetS according to $\mathrm{HbA1c} \geq 5.7 \%$. Compared with individuals with FPG-based diagnosis of MetS, individuals with HbA1c-based diagnosis of MetS were older, had higher levels of LDL-C, magnesium, and transferrin, and lower levels of uric acid. Of those found to have MetS according to either FPG or HbA1c $(n=2008)$, overlap between HbA1c- and FPGbased diagnosis of MetS was limited $(n=768,38.2 \%)$. The overlap index regarding MetS diagnosed by FPG or HbA1c persisted low in each evaluated subgroup $(\leq 50.0 \%)$.

Conclusions: We note limited overlap and poor agreement between FPG- and HbA1c-based diagnosis of MetS. Screening MetS through introduction of HbA1c in addition to FPG could contribute to identification of more people with MetS.

Keywords: Fasting plasma glucose, HbA1c, Metabolic syndrome, CVD risk factors

\section{Background}

The metabolic syndrome (MetS), characterized by abdominal obesity, hypertriglyceridemia, low high-density lipoprotein cholesterol (HDL-C) level, high blood pressure (BP), and increased fasting glucose level, predisposes individuals to a high risk for cardiovascular disease (CVD) and diabetes [1-4]. The MetS is a common disorder in China. According to data from the International Collaborative Study of Cardiovascular Disease in ASIA, 64 (15.1\%) million adults aged 35-74 years have the MetS according to

\footnotetext{
*Correspondence: xfyu188@163.com; lixianxu1237@163.com

${ }^{\dagger}$ Equal contributors

${ }^{2}$ Department of Endocrinology, Tongji Hospital, Tongji Medical College, Huazhong University of Science and Technology, Wuhan, China

'Department of Anesthesiology, School of Stomatology, Fourth Military Medical University, Xi'an, China
}

the modified Adult Treatment Panel III (ATP III) criteria [5]. The ATP III criteria were slightly modified by lowering the threshold for fasting plasma glucose (FPG) to $5.6 \mathrm{mmol} / \mathrm{l}$ in 2004 by the American Heart Association/ National Heart, Lung, and Blood Institute (AHA/NHLBI) $[6,7]$ to be consistent with the American Diabetes Association (ADA) criteria for impaired fasting glucose (IFG) [8]. Most recently, several major organizations, led by the International Diabetes Federation (IDF) and AHA/NHLBI, proposed a unified definition of MetS in 2009 [9], while the ADA recommended the use of glycated hemoglobin (HbA1c) as an alternative to IFG to define the category of increased diabetes risk in 2010 [10]. Studies from the USA and Europe showed that HbA1c can be used instead of

\section{Biomed Central}


FPG in identifying individuals with MetS. However, evidence has suggested that HbA1c value might differ according to ethnic origin [11]. Whether HbA1c can be used instead of FPG in the definition of MetS in Chinese population remains unknown. Hence, we took advantage of the large representative sample of Chinese adults who participated in the China Health and Nutrition Survey (CHNS) 2009 to compare the uses of HbA1c $\geq 5.7 \%$ or FPG $\geq 5.6 \mathrm{mmol} / \mathrm{l}$ in the definition of the glycemic component of MetS. In addition, as prior evidence provided mixed results as to whether the presence of MetS aggravates cardiovascular risk in diabetic patients [12-14], we repeated the analysis in participants without diabetes (FPG $\geq 7.0 \mathrm{mmol} / \mathrm{l}$ or $\mathrm{HbA} 1 \mathrm{c} \geq 6.5 \%$ ).

\section{Methods}

\section{Study design}

The CHNS, which included a sample representative 56\% of the Chinese population, is the only large-scale longitudinal, national survey in China. It was designed to explore how the social and economic transformation of Chinese society is affecting the health and nutritional status of the Chinese population. The CHNS rounds were conducted in 1989, 1991, 1993, 1997, 2000, 2004, 2006, 2009 and 2011. For each round, a stratified multistage, random cluster process was used to draw study sample from nine provinces (Liaoning, Heilongjiang, Jiangsu, Shandong, Henan, Hubei, Hunan, Guangxi and Guizhou) that vary significantly in terms of geography, economic development, and health status. Counties in the nine provinces were stratified by income (low, middle and high) and a weighted sampling scheme was used to select randomly four counties in each province. At last, the CHNS collected health data in 228 communities. Full details of the CHNS have been described elsewhere [15]. Each participant provided a written informed consent and the study was approved by the institutional review committees of the University of North Carolina at Chapel Hill, the National Institute of Nutrition and Food Safety, Chinese Center for Disease Control and Prevention, and the China-Japan Friendship Hospital, Ministry of Health.

\section{Study population}

Since fasting blood samples were initially collected in 2009, this study examined data from the CHNS 2009. The 2009 examination surveyed 10039 participants aged $\geq 18$ years. All participants were asked to complete a structured questionnaire which provided information on age, sex, urban/rural settings, educational attainment, histories of current and previous illness, and medical treatment and so on. Participants were included in the present analysis if they were 18 years or older. Exclusion criteria included pregnancy, a self-reported diabetes diagnosis or diabetes medication use, no information on age, body mass index (BMI), HbA1c, or five components of MetS, and anemia (hemoglobin $<13 \mathrm{~g} / \mathrm{dl}$ in men, and $<12 \mathrm{~g} / \mathrm{dl}$ in women). The remaining available 7641 participants with anthropometry and clinical examination information were included in our analysis.

\section{Anthropometry measurements}

Weight, height, waist circumference (WC) and BP were measured following standardized protocols from the World Health Organization (WHO). Weight was measured with the participants wearing light clothing on a calibrated beam balance and height was measured without shoes using a portable SECA stadiometer (Seca North America East, Hanover, MD, USA). Body mass index (BMI) was calculated as weight (in kilograms) divided by the square of height (in meters). WC was measured with an inelastic tape to the nearest $0.1 \mathrm{~cm}$ at a midpoint between the bottom of the rib cage and the top of the iliac crest at the end of exhalation. BP was measured by trained examiners using a mercury sphygmomanometer with appropriate cuff at three different consecutive times at 3-5 min intervals on one visit. The three readings were averaged as the BP values in our data analysis. All physical examinations were performed at the same location and followed the same protocol.

\section{Biochemical measurements}

Blood was collected after an overnight fast by venipuncture. Samples for FPG and HbA1c measurements were centrifuged and tested immediately. Serum samples for determinations of CVD risk factors, except for FPG and HbA1c, were then frozen, and stored at $-86^{\circ} \mathrm{C}$ for later laboratory analysis. All blood samples were analyzed in a national central lab in Beijing (medical laboratory accreditation certificate ISO15189:2007). Glucose was measured with a Hitachi 7600 analyzer by GOD-PAP method [Randox Laboratories Ltd, UK]. HbA1c was measured with high performance liquid chromatography (HPLC) system [model HLC-723 G7; Tosoh Corporation, Tokyo, Japan]. Lipids (total cholesterol [TC], triglycerides [TG], low density lipoprotein cholesterol [LDL-C], and HDL-C), serum albumin, uric acid, alanine aminotransferase, magnesium, and hypersensitive- $C$ reactive protein (hs-CRP) were measured using a biochemical autoanalyzer (Hitachi 7600 automated analyzer, Tokyo, Japan). Hs-CRP was determined by the immunoturbidimetric method. Fasting insulin concentration was measured using the radioimmunology assay (Gamma counter XH-6020, China). Homeostasis model assessment of insulin resistance (HOMA2-IR) was calculated using the HOMA2 calculator updated in 2007 because it is more accurate than the original HOMA1 method (based on explicit formulas) [16]. 


\section{Definitions}

The MetS was defined according to the consensus criteria in 2009 [9]. Persons with MetS are those with the presence of three or more of the following criteria: elevated WC, defined using population- and country-specific cut points (for Chinese, the cut points for WC were $\geq 85 \mathrm{~cm}$ in men and $\geq 80 \mathrm{~cm}$ in women); TG $\geq 1.7 \mathrm{mmol} / \mathrm{l}$; HDL-C $<1.0 \mathrm{mmol} / \mathrm{l}$ in men and $<1.3 \mathrm{mmol} / \mathrm{l}$ in women; BP $\geq 130 / 85 \mathrm{mmHg}$ or on antihypertensive drug treatment in a patient with a history of hypertension; or FPG $\geq 5.6 \mathrm{mmol} / \mathrm{l}$. According to 2010 ADA criteria [10], dysglycemia is defined as FPG $\geq 5.6 \mathrm{mmol} / \mathrm{l}$ or $\mathrm{HbA} 1 \mathrm{c} \geq 5.7 \%$.

\section{Statistical analysis}

All statistical analyses were performed using SPSS software (version 12.0 for windows; SPSS, Chicago, IL, USA). Continuous variables were presented as mean \pm SD or medians (25th to 75 th percentiles) as appropriate. Categorical variables were presented as numbers and percentages. One-way ANOVA was applied to compare differences in means across groups. Kruskal-Wallis analysis of median test was used followed by the MannWhitney $U$ test for pairwise comparisons. Chi-square test was performed to assess differences in proportions across groups. Bonferroni correction was applied to adjust P-values for multiple comparisons. Analysis were stratified by sex, age groups (18-44 years, 45-64 years, and $\geq 65$ years), urban/rural settings, regions (Southern [Jiangsu, Hubei, Hunan, Guangxi, Guizhou]/Northern [Liaoning, Heilongjiang, Shandong, Henan]), educational attainments (Primary or below, less than high school, high school or above), BMI categories, WC groups, and $\mathrm{BP}$ status. The uses of $\mathrm{HbA} 1 \mathrm{c} \geq 5.7 \%$ or FPG $\geq 5.6 \mathrm{mmol} / \mathrm{l}$ in the definition of the glycemic component of MetS were compared. The kappa (к) statistic was calculated to test for an agreement between FPG- and HbA1c-based identification of MetS. Venn diagram was constructed as a visual display of concordance/discordance between FPG- and HbA1c-based identification of MetS. The diagnostic property of $\mathrm{HbA} 1 \mathrm{c} \geq 5.7 \%$ in identifying MetS was evaluated by receiver operating characteristic (ROC) curve. A two-tailed $\mathrm{P}$ value of $<0.05$ was considered to be significant.

\section{Results}

\section{Prevalence of metabolic syndrome}

Of the 7641 persons without a history of diabetes, 1136 (14.9\%) met MetS using the FPG criterion, and 1640 (21.5\%) met MetS using the HbA1c criterion. The proportion of FPG-based diagnosis of MetS remained stable between genders $(15.0 \%$ in men and $14.8 \%$ in women, $\mathrm{P}=0.63$ ), while women had a significantly higher proportion of HbA1c-based diagnosis of MetS than men $(19.7 \%$ in men and $23.0 \%$ in women, $\mathrm{P}<0.001)$. The prevalence of FPG- and HbA1c-based diagnosis of MetS increased with age (Table 1). However, the age-related gradient was notably steeper for $\mathrm{HbA1c}$-based definition of MetS than FPG-based definition of MetS. For each age group, the prevalence of HbA1c-based identification of MetS was significantly higher than that of FPG-based definition of MetS. Similar significant trends were noted in urban/rural settings, regions, all education groups, BMI and WC categories, and all BP status.

\section{Overlap between FPG- and HbA1c-based definition of metabolic syndrome}

Of those found to have MetS by either FPG or HbA1c ( $\mathrm{n}=2008,26.3 \%)$, overlap between HbA1c- and FPGbased diagnosis of MetS was limited ( $n=768,38.2 \%)$ (Figure 1). The $\kappa$ coefficient of the FPG criterion with HbA1c criterion for the diagnosis of MetS was 0.458 . Using FPG-based diagnosis of MetS as the reference standard, the HbA1c cut-point of $5.7 \%$ in identifying subjects with MetS demonstrated a sensitivity of $60.3 \%$, specificity of $76.2 \%$, positive predictive value of $30.6 \%$, and negative predictive value of $91.7 \%$. ROC curve analysis with $\mathrm{HbA1c}$ as a continuous variable yielded an area under the curve of $0.74(\mathrm{P}<0.01)$. The overlap index regarding MetS diagnosed by FPG and HbA1c was low irrespective of sex, age, urban/rural setting, region, educational attainment, BMI, WC and BP status (Table 2). The magnitude of overlap between the two criteria slightly increased with increasing age, worsening BMI, WC, and BP.

Similar to the overall cohort, in the non-diabetes group, overlap between HbA1c- and FPG-based diagnosis of MetS was even more limited (5.9\%). The $\kappa$ coefficient of the FPG criterion with HbA1c criterion for the diagnosis of MetS was 0.322 .

\section{Characteristics of individuals diagnosed with metabolic syndrome by each measure}

As expected, the worst CVD risk profile was found in individuals with MetS based upon both FPG and HbA1c and the most favorable cardiovascular profile was found in individuals without MetS (Table 3). The characteristics differed for individuals with FPG-based diagnosis of MetS compared with participants with HbA1c-based diagnosis of MetS. Specifically, participants with HbA1cbased diagnosis of MetS were older, had higher levels of HbA1c, LDL-C, magnesium, and transferrin, and lower levels of FPG, and uric acid. Results were largely replicated when the same analysis were conducted in the non-diabetes group (Additional file 1).

\section{Discussion}

In the present study, we compared HbA1c and FPG in the definition of glycemic component of MetS. We saw low magnitude of overlap and poor agreement between 
Table 1 Prevalence of metabolic syndrome (MetS) according to fasting plasma glucose or HbA1c or both

\begin{tabular}{|c|c|c|c|c|c|}
\hline & No MetS & $\begin{array}{c}\text { FPG-based diagnosis of } \\
\text { MetS }\end{array}$ & $\begin{array}{l}\text { HbA1c-based diagnosis of } \\
\text { MetS }\end{array}$ & $\begin{array}{c}\text { MetS by both FPG and } \\
\text { HbA1c }\end{array}$ & к coefficient ${ }^{*}$ \\
\hline$\overline{A L L}$ & $5633(73.7)$ & $368(4.8)$ & $872(11.4)$ & $768(10.1)$ & 0.458 \\
\hline \multicolumn{6}{|l|}{ Sex } \\
\hline Men & $2731(75.3)$ & $179(5.0)$ & $353(9.7)$ & $361(10.0)$ & 0.489 \\
\hline Women & $2902(72.3)$ & $189(4.7)$ & 519 (12.9) & $407(10.1)$ & 0.432 \\
\hline \multicolumn{6}{|l|}{ Age, y } \\
\hline $18-44$ & 2434 (86.6) & $88(3.1)$ & $176(6.3)$ & $113(4.0)$ & 0.412 \\
\hline $45-64$ & $2407(68.4)$ & $214(6.1)$ & 475 (13.5) & $423(12.0)$ & 0.431 \\
\hline$\geq 65$ & $792(60.5)$ & $66(5.0)$ & $221(16.8)$ & $232(17.7)$ & 0.474 \\
\hline \multicolumn{6}{|l|}{ BMI categories } \\
\hline$<25 \mathrm{~kg} / \mathrm{m}^{2}$ & $4462(83.1)$ & $189(3.5)$ & $409(7.6)$ & $310(5.8)$ & 0.449 \\
\hline $25-30 \mathrm{~kg} / \mathrm{m}^{2}$ & $1056(53.9)$ & $148(7.6)$ & $395(20.2)$ & $359(18.3)$ & 0.376 \\
\hline$\geq 30 \mathrm{~kg} / \mathrm{m}^{2}$ & $115(36.8)$ & $31(9.9)$ & $68(21.7)$ & 99 (31.6) & 0.375 \\
\hline \multicolumn{6}{|l|}{ WC categories } \\
\hline$<85 / 80 \mathrm{~cm}$ & 3507 (93.6) & $44(1.2)$ & $119(3.2)$ & $72(2.0)$ & 0.448 \\
\hline$\geq 85 / 80 \mathrm{~cm}$ & $2126(54.5)$ & $324(8.3)$ & 753 (19.3) & $696(17.9)$ & 0.371 \\
\hline \multicolumn{6}{|l|}{ BP status } \\
\hline$<120 / 80 \mathrm{mmHg}$ & 2159 (91.5) & $46(2.0)$ & $101(4.3)$ & $53(2.2)$ & 0.388 \\
\hline $\begin{array}{l}120 / 80-140 / \\
90 \mathrm{mmHg}\end{array}$ & $2532(75.9)$ & $150(4.5)$ & $346(10.4)$ & $307(9.2)$ & 0.467 \\
\hline$\geq 140 / 90 \mathrm{mmHg}$ & $942(48.4)$ & $172(8.8)$ & $425(21.8)$ & $408(21.0)$ & 0.349 \\
\hline \multicolumn{6}{|l|}{ Settings } \\
\hline Urban & 1785 (72.8) & $146(5.9)$ & $287(11.7)$ & 236 (9.6) & 0.412 \\
\hline Rural & $3848(74.2)$ & $222(4.3)$ & 585 (11.3) & $532(10.2)$ & 0.478 \\
\hline \multicolumn{6}{|l|}{ Regions } \\
\hline Southern & 3438 (78.9) & $224(5.1)$ & $392(9.0)$ & $304(7.0)$ & 0.416 \\
\hline Northern & $2195(66.9)$ & $144(4.4)$ & $480(14.6)$ & $464(14.1)$ & 0.481 \\
\hline \multicolumn{6}{|l|}{ Education } \\
\hline Primary or below & $2367(69.5)$ & $171(5.0)$ & $471(13.8)$ & $396(11.7)$ & 0.439 \\
\hline $\begin{array}{l}\text { Less than high } \\
\text { school }\end{array}$ & $1900(76.9)$ & $121(4.9)$ & $232(9.3)$ & 220 (8.9) & 0.472 \\
\hline $\begin{array}{l}\text { High school or } \\
\text { above }\end{array}$ & 1366 (77.5) & $76(4.3)$ & 169 (9.6) & 152 (8.6) & 0.474 \\
\hline
\end{tabular}

Data are numbers (percentages).

*An agreement between FPG- and HbA1c- based identification of MetS.

$\mathrm{FPG}$, fasting plasma glucose; BMI, body mass index; WC, waist circumference; BP, blood pressure.

FPG- and HbA1c-based identification of MetS. Similar significant trends were noted in each evaluated subgroup. The prevalence of $\mathrm{HbA1c}$-based diagnosis of MetS was significantly higher than FPG-based diagnosis of MetS. Screening MetS by introduction of the new HbA1c criterion in addition to assessment of the FPG could contribute to identification of more people with MetS.

Our results are in line with the study from an European country with respect to a higher prevalence of MetS measured by HbA1c than by FPG [17]. Evidence has suggested that there were a large proportion of Chinese with isolated postprandial hyperglycemia [18]. Although postprandial glucose were not available in the present study, it is possible that even with normal fasting glucose, individuals may have postprandial hyperglycemia. HbA1c represents chronic exposure to basal and postprandial hyperglycemia. Hence, HbA1c can identify more individuals with MetS than FPG.

In the present $\mathrm{CHNS}$ cohort, $\mathrm{HbA1c}$-based diagnosis of MetS illustrated limited overlap with FPG-based diagnosis of MetS. This deviates from the findings of the cohort 


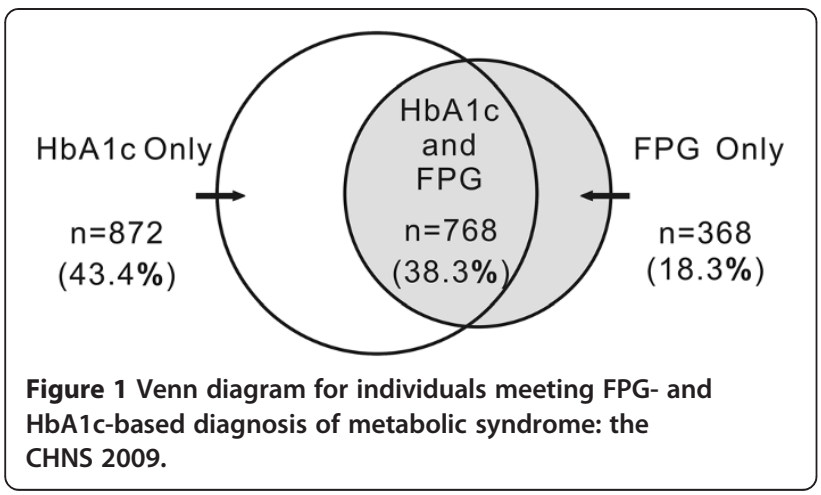

studies from United States and European countries in which a good agreement between HbA1c- and FPG-based identification of MetS was observed [17,19]. Hence, a discrepancy in the degree of overlap might be more likely to happen in Chinese than in US and European adults. The inconsistency between the cited studies and our present study may be attributed to the discrepancies in ethnicity, socio-demographic or personal characteristics, prevalence of CVD risk factors such as hypertension, obesity, hypertriglyceridemia, and lifestyle differences. Another possible explanation for the inconsistency might be due to the fact that FPG differentially correlated with HbA1c among different ethnic populations as several recent

Table 2 Proportions of metabolic syndrome (MetS) by fasting plasma glucose only, HbA1c only, and by both criteria

\begin{tabular}{|c|c|c|c|c|}
\hline & $\begin{array}{c}\text { MetS by either FPG or } \\
\text { HbA1c }\end{array}$ & $\begin{array}{c}\text { FPG-based diagnosis of } \\
\text { MetS }\end{array}$ & $\begin{array}{l}\text { HbA1c-based diagnosis of } \\
\text { MetS }\end{array}$ & $\begin{array}{c}\text { MetS by both FPG and HbA1c } \\
\text { (overlap*) }\end{array}$ \\
\hline \multicolumn{5}{|l|}{ Sex } \\
\hline Men & 893 & $179(20.0)$ & $353(39.5)$ & $361(40.4)$ \\
\hline Women & 1115 & $189(17.0)$ & $519(46.5)$ & $407(36.5)$ \\
\hline \multicolumn{5}{|l|}{ Age, y } \\
\hline $18-44$ & 377 & $88(23.3)$ & $176(46.7)$ & $113(30.0)$ \\
\hline $45-64$ & 1112 & $214(19.2)$ & $475(42.7)$ & $423(38.0)$ \\
\hline$\geq 65$ & 519 & $66(12.7)$ & $221(42.6)$ & $232(44.7)$ \\
\hline \multicolumn{5}{|l|}{ BMI categories } \\
\hline$<25 \mathrm{~kg} / \mathrm{m}^{2}$ & 908 & $189(20.8)$ & $409(45.0)$ & $310(34.1)$ \\
\hline $25-30 \mathrm{~kg} / \mathrm{m}^{2}$ & 902 & $148(16.4)$ & $395(43.8)$ & $359(39.8)$ \\
\hline$\geq 30 \mathrm{~kg} / \mathrm{m}^{2}$ & 198 & $31(15.7)$ & 68 (34.3) & $99(50.0)$ \\
\hline \multicolumn{5}{|l|}{ WC categories } \\
\hline$<85 / 80 \mathrm{~cm}$ & 235 & 44 (18.7) & $119(50.6)$ & $72(30.6)$ \\
\hline$\geq 85 / 80 \mathrm{~cm}$ & 1773 & $324(18.3)$ & $753(42.5)$ & $696(39.3)$ \\
\hline \multicolumn{5}{|l|}{ BP status } \\
\hline$<120 / 80 \mathrm{mmHg}$ & 200 & $46(23.0)$ & $101(50.5)$ & $53(26.5)$ \\
\hline $\begin{array}{l}120 / 80-140 / \\
90 \mathrm{mmHg}\end{array}$ & 803 & $150(18.7)$ & $346(43.1)$ & 307 (38.2) \\
\hline$\geq 140 / 90 \mathrm{mmHg}$ & 1005 & $172(17.1)$ & $425(42.3)$ & $408(40.6)$ \\
\hline \multicolumn{5}{|l|}{ Settings } \\
\hline Urban & 669 & $146(21.8)$ & $287(42.9)$ & $236(35.3)$ \\
\hline Rural & 1339 & $222(16.6)$ & $585(43.7)$ & $532(39.7)$ \\
\hline \multicolumn{5}{|l|}{ Regions } \\
\hline Southern & 920 & $224(24.3)$ & $392(42.6)$ & $304(33.0)$ \\
\hline Northern & 1088 & $144(13.2)$ & $480(44.1)$ & $464(42.6)$ \\
\hline \multicolumn{5}{|l|}{ Education } \\
\hline Primary or below & 1038 & $171(16.5)$ & $471(45.4)$ & 396 (38.2) \\
\hline $\begin{array}{l}\text { Less than high } \\
\text { school }\end{array}$ & 573 & $121(21.1)$ & $232(40.5)$ & $220(38.4)$ \\
\hline $\begin{array}{l}\text { High school or } \\
\text { above }\end{array}$ & 397 & 76 (19.1) & 169 (42.6) & $152(38.3)$ \\
\hline
\end{tabular}

"Proportions of overlap between HbA1c- and FPG-based diagnosis of MetS are calculated as the number of MetS by both FPG and HbA1c divided by the number of MetS based on either FPG or HbA1c.

FPG, fasting plasma glucose; BMI, body mass index; WC, waist circumference; BP, blood pressure. 
Table 3 Characteristics of participants stratified by diagnosis of metabolic syndrome (MetS) according to fasting plasma glucose or HbA1c or both

\begin{tabular}{|c|c|c|c|c|}
\hline & No MetS & FPG-based diagnosis of MetS & HbA1c-based diagnosis of MetS & $\begin{array}{c}\text { MetS by both FPG } \\
\text { and HbA1c }\end{array}$ \\
\hline Female (\%) & 51.5 & 51.4 & 59.5 & 53.0 \\
\hline Age $(\text { years })^{\S}$ & $48.2 \pm 15.0^{*+\neq}$ & $53.6 \pm 12.2^{*}$ & $56.1 \pm 13.2^{*}$ & $58.2 \pm 12.1$ \\
\hline Body mass index $\left(\mathrm{kg} / \mathrm{m}^{2}\right)^{\S}$ & $22.6 \pm 3.1^{*} \neq$ & $25.3 \pm 3.1^{*}$ & $25.4 \pm 3.1^{*}$ & $26.1 \pm 3.4$ \\
\hline Waist circumference $(\mathrm{cm})^{\S}$ & $79.8 \pm 9.4^{* \dagger \neq}$ & $89.1 \pm 8.0^{*}$ & $89.3 \pm 8.4^{*}$ & $91.5 \pm 8.7$ \\
\hline Systolic blood pressure $(\mathrm{mmHg})$ & $120.0(110.0-128.7)^{* \dagger \neq}$ & $130.0(120.0-142.3)^{*}$ & $131.0(120.0-144.7)^{*}$ & $136.0(123.3-149.3)$ \\
\hline Diastolic blood pressure $(\mathrm{mmHg})$ & $79.3(70.7-83.3)^{*}+\neq$ & $85.0(80.0-90.7)$ & $86.0(80.0-91.0)$ & $86.7(80.0-91.8)$ \\
\hline Fasting plasma glucose $(\mathrm{mmol} / \mathrm{l})$ & $4.9(4.6-5.3)^{*}+\neq$ & $5.9(5.7-6.3)$ & $5.0(4.7-5.3)^{*+}$ & $6.4(5.9-7.5)$ \\
\hline HbAlc (\%) & $5.4(5.1-5.6)^{*} \neq$ & $5.4(5.2-5.5)^{*}$ & $5.9(5.8-6.1)^{*+}$ & $6.2(5.9-6.8)$ \\
\hline Total cholesterol (mmol/l) & $4.7(4.1-5.3)^{*} \neq$ & $4.9(4.3-5.7)^{*}$ & $5.0(4.5-5.7)^{*}$ & $5.3(4.7-6.0)$ \\
\hline Triglycerides (mmol/l) & $1.1(0.8-1.5)^{*+\neq}$ & $2.0(1.3-2.7)$ & $1.8(1.2-2.5)$ & $1.9(1.3-2.8)$ \\
\hline LDL cholesterol (mmol/l) & $2.8(2.3-3.4)^{*+\neq}$ & $3.0(2.3-3.5)^{*}$ & $3.1(2.5-3.8)^{\dagger}$ & $3.3(2.6-3.9)$ \\
\hline HDL cholesterol $(\mathrm{mmol} / \mathrm{l})$ & $1.4(1.2-1.7)^{*+\neq}$ & $1.2(1.0-1.5)$ & $1.2(1.1-1.5)$ & $1.2(1.0-1.4)$ \\
\hline Uric acid (mmol/l) & $286.0(233.0-349.0)^{*+\neq}$ & $336.5(281.5-411.0)$ & $318.0(256.0-377.0))^{*}$ & $328.0(267.0-393.0)$ \\
\hline HOMA2-IR & $1.3(0.9-1.8)^{*+\neq}$ & $1.9(1.4-2.9)^{*}$ & $1.6(1.2-2.2)^{*}$ & $2.2(1.5-3.5)$ \\
\hline Hemoglobin ( $g / d l)$ & $141.0(130.0-153.0)^{*+}$ & $145.0(133.0-157.0)$ & $142.0(131.0-154.0)^{*}$ & $146.0(135.0-159.0)$ \\
\hline Albumin (g/dl) & $47.3(45.3-49.5)$ & $47.5(45.5-49.7)$ & $47.3(45.3-49.3)$ & $47.8(45.7-49.8)$ \\
\hline Alanine aminotransferase (UI/L) & $17.0(13.0-25.0)^{*}+\neq$ & $21.0(14.0-31.5)^{*}$ & $21.0(15.0-29.0)^{*}$ & $23.0(17.0-32.5)$ \\
\hline $\begin{array}{l}\text { Estimated glomerular filtration rate } \\
\left(\mathrm{ml} / \mathrm{min} \text { per } 1.73 \mathrm{~m}^{2}\right)\end{array}$ & $76.7(68.2-86.6)^{*+}$ & $73.7(65.0-82.8)$ & $74.4(66.2-83.3)$ & $72.8(63.4-82.2)$ \\
\hline C-reactive protein (mg/l) & $1.0(0.0-2.0)^{*}$ & $1.0(1.0-3.0)^{*}$ & $2.0(1.0-3.0)$ & $2.0(1.0-4.0)$ \\
\hline Serum magnesium & $0.9(0.9-1.0)^{*}$ & $0.9(0.9-1.0)^{*}$ & $1.0(0.9-1.0)^{\dagger}$ & $1.0(0.9-1.0)$ \\
\hline Transferrin (ng/ml) & $2.8(2.5-3.1)^{* \neq}$ & $2.8(2.5-3.1)^{*}$ & $2.9(2.6-3.3)^{\dagger}$ & $3.0(2.6-3.3)$ \\
\hline Soluble Transferrin receptor $(\mathrm{ng} / \mathrm{ml})$ & $1.3(1.1-1.6)$ & $1.3(1.1-1.7)$ & $1.3(1.0-1.6)$ & $1.3(1.1-1.6)$ \\
\hline White blood cell count $\left(\times 10^{9} / \mathrm{ml}\right)$ & $6.0(5.0-7.1)^{*}$ & $6.1(5.1-7.3)^{*}$ & $6.2(5.3-7.5)^{*}$ & $6.5(5.6-7.7)$ \\
\hline
\end{tabular}

Data are medians (25th to 75 th percentiles) or percent, except variables denoted by ${ }^{\S}$, which are means \pm SD

${ }^{*} \mathrm{P}<0.001$ compared with individuals with MetS according to both FPG and $\mathrm{HbA1c}$.

${ }^{\dagger} \mathrm{P}<0.001$ compared with individuals with MetS according to FPG only.

${ }^{\ddagger} \mathrm{P}<0.001$ compared with individuals with MetS according to HbA1c only.

reports have compared the relationship of HbA1c to FPG in various populations and have found significant discordance $[11,20]$. HbA1c correlates better with insulin resistance than FPG [21]. To date, differences in the relation of FPG and HbA1c to insulin resistance and insulin secretion have been little described in Chinese population. One study conducted in Japanese population indicated that high normal HbA1c levels (5.4$5.8 \%)$ were associated with impaired insulin secretion without marked insulin resistance and elevated HbA1c levels $(\geq 5.9 \%)$ were associated with substantial impairment in insulin secretion, insulin sensitivity and $\beta$-cell dysfunction [21], while one Chinese population based study suggested that increased FPG is predominately induced by the decline in insulin sensitivity and insulin secretion, with the insulin secretion more pronounced [22]. Taken together, it is possible that how well HbA1c performs as compared with FPG for the identification of MetS will depend on the target population.

The limited overlap between HbA1c- and FPG-based diagnosis of MetS highlights different facets of glucose metabolism and multifactorial pathophysiologic mechanisms for glucose dysfunction [23-25]. In contrast to daily preprandial glucose snapshot offered by FPG, HbA1c captures chronic hyperglycemia, including postprandial glucose spikes. Increased FPG is predominately induced by liver insulin resistance and a defect in the early phase of insulin secretion [23,25], whereas increased HbA1c is dominated by a combination of hepatic insulin resistance, muscle insulin resistance and impaired insulin secretion $[24,25]$. Although the explanations for the significantly higher proportion of HbA1c-based diagnosis of MetS in women compared with men observed in the present study remain to be elucidated, it is probably related to gender 
differences in glucose absorption patterns [26]. The difference in gender-specific glucose absorption pattern is a consequence of the relatively higher dose of glucose given to women compared with men when seen in relation to their body size $[27,28]$. Several studies have shown that men in general have a higher prevalence of isolated impaired fasting glucose than do women $[27,28]$. In contrast, women often exhibit a higher prevalence of isolated impaired glucose tolerance $[27,28]$. Monnier et al. found that the relative contribution of postprandial hyperglycemia accounted for $\sim 70 \%$ of overall glycemic exposure in patients with HbAlc $<7.3 \%$, while the relative contribution of FPG increased gradually with increasing levels of HbA1c [29]. In the present study, we noted that only $8(0.9 \%)$ individuals had HbA1c $\geq 7.3 \%$ among the 872 individuals with HbA1cbased definition of MetS (data not shown), indicating a greater contribution of postprandial versus FPG to HbA1c levels. Hence, the HbA1c-based definition of MetS reflects more of the postprandial glucose-based diagnosis of MetS. Taken together, it is possible that women carry a higher prevalence of HbA1c-based diagnosis of MetS than do men. A greater contribution of postprandial versus FPG to HbA1c levels may also in part explain the limited overlap between FPG and HbA1c-based definition of MetS.

Subgroup differences were noted in the present study, with a slightly higher magnitude of overlap between FPG and $\mathrm{HbA1c}$-based definition of MetS among persons with older age, elevated BMI, WC, and BP. One possible explanation for this relatively low discrepancy in older age might be the fact that the prevalence of MetS was more frequent among older persons $[5,30]$. The relatively low discrepancy in worsening BMI, WC, and BP status might be attributed to the fact that obesity, enlarged waist, and hypertension accompany the insulinresistant state that underlies the MetS.

In this study, individuals with FPG-based identification of MetS had different characteristics compared with individuals with $\mathrm{HbA1c}$-based identification of MetS. The different characteristics might affect progression to CVD mortality and morbidity within each case of discordantly diagnosed MetS. Most components of the MetS are required to be conducted in the fasting state, although an overnight fast is not required for HbA1c measurement, it is possible that clinicians can have access to both FPG and HbA1c in most of their patients. In this context, and based on our data, the MetS rate may increase by approximately $70 \%$ if both FPG and HbA1c are measured. Although there is controversy whether the diagnosis of MetS conveys additional cardiovascular risk in subjects with diabetes [12-14], a recent meta-analysis evidenced that in the absence of type 2 diabetes mellitus, the MetS was associated with an increased risk of cardiovascular mortality (RR: 1.75 ; 95\% CI: 1.19 to 2.58 ) [3]. Our present study showed that in participants without diabetes, even more limited overlap between HbA1c- and FPG-based diagnosis of MetS was observed. The identification of MetS is of clinical importance because appropriate interventions can clearly prevent or delay the CVD mortality and morbidity, especially in subjects without diabetes. Although evidence suggested that there was no linear relationship between FPG and CVD mortality and morbidity [31], the risk for diabetes and CVD mortality and morbidity increased gradually with rising FPG and HbA1c $[32,33]$. Two prospective studies demonstrated that the combined use of FPG and HbA1c were more predictive of the risk of future diabetes [34,35]. Our finding that individuals with Mets based on both FPG and HbA1c were older, more obese, hypertensive, dyslipidemic, and insulin resistant and had higher CRP compared with individuals with Mets based on FPG alone or HbA1c alone further supported the notion. Therefore, individuals with Mets based on both measure might allow for assessment of a substantially increased risk of CVD mortality and morbidity. We believe that introduction of HbA1c into FPG is appropriate for detection of MetS, and will contribute to cover a larger number of people being submitted to aggressive drug regimens to prevent future risk for diabetes and CVD mortality and morbidity. Further large-scale longitudinal studies are, however, required to address this issue.

Our study has several strengths including a wellestablished cohort of nationally representative sample of the Chinese adult population, a vigorous quality assurance program, the same strict methodology used to ensure the quality of the data collection over the entire study period, and the centralization of laboratory measurements. We also benefited from the CHNS 2009's availability of broad range of demographic, clinical, and biomarker data collected by trained staff. Nevertheless, the current study was subjected to several limitations. First, we got availability of only single measures of all biochemical variables, a common limitation to most large epidemiologic studies. Second, since the current study is a cross-sectional design, we cannot explore whether diagnosis of MetS based on different measures have the same predictive capacity in the risk of future diabetes and CVD mortality and morbidity. Third, estimates across subgroups should also be interpreted with caution because of limited sample size.

\section{Conclusion}

In summary, limited overlap and poor agreement are demonstrated between the FPG- and HbA1c-based diagnosis of MetS. Screening MetS through introduction of HbA1c in addition to FPG could contribute to identification of more people with MetS who would otherwise have been missed. 


\section{Additional file}

\section{Additional file 1: Characteristics of CHNS 2009 participants stratified by diagnosis of MetS according to fasting plasma glucose or $\mathrm{HbA} 1 \mathrm{c}$ or both in participants without diabetes.}

\section{Abbreviations}

MetS: Metabolic syndrome; HbA1c: Glycated hemoglobin; FPG: Fasting plasma glucose; HDL-C: High-density lipoprotein cholesterol; BP: Blood pressure; CVD: Cardiovascular disease; CHNS: China Health and Nutrition Survey; WC: Waist circumference; BMI: Body mass index; TC: Total cholesterol; TG: Triglycerides; LDL-C: Low density lipoprotein cholesterol; hs-CRP: Hypersensitive-C reactive protein; HOMA-IR: Homeostasis model assessment of insulin resistance; HOMA- $\beta$ : Homeostasis model assessment of beta-cell function.

\section{Competing interests}

No potential conflicts of interest relevant to this article were reported. The authors declare that they have no competing interests.

\section{Authors' contributions}

XXS and TTD conceived the study, completed all statistical analyses, and drafted the manuscript. LXX, XFY and RH contributed to the discussion. $L X X$ and $X F Y$ revised the manuscript. All authors have read and approved the final manuscript.

\section{Acknowledgments}

We thank the China Health and Nutrition Survey, supported by the NIH (R01-HD30880, DK056350 and R01-HD38700), and the National Institute of Nutrition and Food Safety, China Center for Disease Control and Prevention, Carolina Population Center, the University of North Carolina at Chapel Hill and the Fogarty International Center for providing the data used here. We also thank the China-Japan Friendship Hospital and Ministry of Health for support for CHNS 2009 survey. All errors are the authors' alone.

\section{Received: 13 May 2013 Accepted: 31 October 2013}

Published: 5 November 2013

\section{References}

1. Wilson PW, D'Agostino RB, Parise H, Sullivan L, Meigs JB: Metabolic syndrome as a precursor of cardiovascular disease and type 2 diabetes mellitus. Circulation 2005, 112:3066-3072.

2. Lakka HM, Laaksonen DE, Lakka TA, Niskanen LK, Kumpusalo E, Tuomilehto J, Salonen JT: The metabolic syndrome and total and cardiovascular disease mortality in middle-aged men. JAMA 2002, 288:2709-2716.

3. Mottillo S, Filion KB, Genest J, Joseph L, Pilote L, Poirier P, Rinfret S, Schiffrin EL, Eisenberg MJ: The metabolic syndrome and cardiovascular risk a systematic review and meta-analysis. J Am Coll Cardiol 2010, 56:1113-1132.

4. Wannamethee SG, Shaper AG, Lennon L, Morris RW: Metabolic syndrome vs Framingham Risk Score for prediction of coronary heart disease, stroke, and type 2 diabetes mellitus. Arch Int Med 2005, 165:2644-2650.

5. Gu D, Reynolds K, Wu X, Chen J, Duan X, Reynolds RF, Whelton PK, He J, Inter ACG: Prevalence of the metabolic syndrome and overweight among adults in China. Lancet 2005, 365:1398-1405.

6. Grundy SM, Brewer HB Jr, Cleeman JI, Smith SC Jr, Lenfant C: Definition of metabolic syndrome: Report of the National Heart, Lung, and Blood Institute/American Heart Association conference on scientific issues related to definition. Circulation 2004, 109:433-438.

7. Grundy SM, Cleeman J, Daniels SR, Donato KA, Eckel RH, Franklin BA, Gordon DJ, Krauss RM, Savage PJ, Smith SC Jr, et al: Diagnosis and management of the metabolic syndrome: an American Heart Association/National Heart, Lung, and Blood Institute Scientific Statement. Circulation 2005, 112:2735-2752

8. Genuth S, Alberti KG, Bennett P, Buse J, Defronzo R, Kahn R, Kitzmiller J, Knowler WC, Lebovitz H, Lernmark A, et al: Follow-up report on the diagnosis of diabetes mellitus. Diabetes Care 2003, 26:3160-3167.

9. Alberti KG, Eckel RH, Grundy SM, Zimmet PZ, Cleeman II, Donato KA, Fruchart JC, James WP, Loria CM, Smith SC Jr: Harmonizing the metabolic syndrome: a joint interim statement of the International Diabetes
Federation Task Force on Epidemiology and Prevention; National Heart, Lung, and Blood Institute; American Heart Association; World Heart Federation; International Atherosclerosis Society; and International Association for the Study of Obesity. Circulation 2009, 120:1640-1645.

10. American Diabetes Association: Diabetes Care 2010, 33(Suppl 1):S62-S69.

11. Herman WH, Ma Y, Uwaifo G, Haffner S, Kahn SE, Horton ES, Lachin JM Montez MG, Brenneman T, Barrett-Connor E, et al: Differences in A1C by race and ethnicity among patients with impaired glucose tolerance in the Diabetes Prevention Program. Diabetes Care 2007, 30:2453-2457.

12. Hadaegh F, Shafiee G, Ghasemi A, Sarbakhsh P, Azizi F: Impact of metabolic syndrome, diabetes and prediabetes on cardiovascular events: Tehran lipid and glucose study. Diab Res Clin Pract 2010, 87:342-347.

13. Bonora E, Targher G, Formentini G, Calcaterra F, Lombardi S, Marini F, Zenari $L$, Saggiani F, Poli M, Perbellini S, et al: The metabolic syndrome is an independent predictor of cardiovascular disease in type 2 diabetic subjects. Prospective data from the Verona diabetes complications study. Diab Med 2004, 21:52-58.

14. Church TS, Thompson AM, Katzmarzyk PT, Sui X, Johannsen N, Earnest CP, Blair SN: Metabolic syndrome and diabetes, alone and in combination, as predictors of cardiovascular disease mortality among men. Diabetes Care 2009, 32:1289-1294.

15. Popkin BM, Du S, Zhai F, Zhang B: Cohort Profile: The China Health and Nutrition Survey-monitoring and understanding socio-economic and health change in China, 1989-2011. Int J Epidemiol 2010, 39:1435-1440.

16. Wallace TM, Levy JC, Matthews DR: Use and abuse of HOMA modeling. Diabetes Care 2004, 27:1487-1495.

17. Succurro E, Marini MA, Arturi F, Grembiale A, Fiorentino TV, Andreozzi F, Sciacqua A, Lauro R, Hribal ML, Perticone F, et al: Usefulness of hemoglobin A1C as a criterion to define the metabolic syndrome in a cohort of italian nondiabetic white subjects. Am J Cardiol 2011, 107:1650-1655.

18. Yang W, Lu J, Weng J, Jia W, Ji L, Xiao J, Shan Z, Liu J, Tian H, Ji Q, et al: Prevalence of diabetes among men and women in China. N Engl J Med 2010, 362:1090-1101.

19. Ong KL, Tso AW, Lam KS, Cherny SS, Sham PC, Cheung BM: Using glycosylated hemoglobin to define the metabolic syndrome in United States adults. Diabetes Care 2010, 33:1856-1858.

20. Ziemer DC, Kolm P, Weintraub WS, Vaccarino V, Rhee MK, Twombly JG, Narayan KM, Koch DD, Phillips LS: Glucose-independent, black-white differences in hemoglobin A1c levels: a cross-sectional analysis of 2 studies. Ann Intern Med 2010, 152:770-777.

21. Heianza $Y$, Arase $Y$, Fujihara K, Tsuji H, Saito K, Hsieh SD, Kodama S, Shimano $\mathrm{H}$, Yamada N, Hara S, et al: High normal HbA(1c) levels were associated with impaired insulin secretion without escalating insulin resistance in Japanese individuals: the Toranomon Hospital Health Management Center Study 8 (TOPICS 8). Diab Med 2012, 29:1285-1290.

22. Bi Y, Zeng L, Zhu D, Yan J, Zhang Y, Tong G, Mu P, Shen S, Hu Y, Yu Q, et al: Association of beta-cell function and insulin sensitivity with fasting and 2-h plasma glucose in a large Chinese population. Diab Obes Metab 2012 $14: 174-180$

23. Nathan DM, Davidson MB, DeFronzo RA, Heine RJ, Henry RR, Pratley R, Zinman B, American Diabetes A: Impaired fasting glucose and impaired glucose tolerance: implications for care. Diabetes Care 2007, 30:753-759.

24. Goldstein DE, Little RR, Lorenz RA, Malone II, Nathan D, Peterson CM, Sacks DB: Tests of glycemia in diabetes. Diabetes Care 2004, 27:1761-1773.

25. Abdul-Ghani MA, Jenkinson CP, Richardson DK, Tripathy D, DeFronzo RA: Insulin secretion and action in subjects with impaired fasting glucose and impaired glucose tolerance: results from the Veterans Administration Genetic Epidemiology Study. Diabetes 2006, 55:1430-1435.

26. Faerch K, Pacini G, Nolan JJ, Hansen T, Tura A, Vistisen D: Impact of glucose tolerance status, Sex, and body size on glucose absorption patterns during OGTTs. Diabetes care 2013, 36:3691-3697.

27. Faerch K, Borch-Johnsen K, Vaag A, Jorgensen T, Witte DR: Sex differences in glucose levels: a consequence of physiology or methodological convenience? The Inter99 study. Diabetologia 2010, 53:858-865.

28. Williams JW, Zimmet PZ, Shaw JE, de Courten MP, Cameron AJ, Chitson P, Tuomilehto J, Alberti KG: Gender differences in the prevalence of impaired fasting glycaemia and impaired glucose tolerance in Mauritius. Does sex matter? Diab Med 2003, 20:915-920.

29. Monnier L, Lapinski $H$, Colette $C$ : Contributions of fasting and postprandial plasma glucose increments to the overall diurnal hyperglycemia of type 
2 diabetic patients: variations with increasing levels of $\mathrm{HbA}(1 \mathrm{c})$ Diabetes Care 2003, 26:881-885.

30. Ford ES, Giles WH, Dietz WH: Prevalence of the metabolic syndrome among US adults: findings from the third National Health and Nutrition Examination Survey. JAMA 2002, 287:356-359.

31. Emerging Risk Factors C, Sarwar N, Gao P, Seshasai SR, Gobin R, Kaptoge S, Di Angelantonio E, Ingelsson E, Lawlor DA, Selvin E, et al: Diabetes mellitus, fasting blood glucose concentration, and risk of vascular disease: a collaborative meta-analysis of 102 prospective studies. Lancet 2010, 375:2215-2222

32. Droumaguet C, Balkau B, Simon D, Caces E, Tichet J, Charles MA, Eschwege $\mathrm{E}:$ Use of $\mathrm{HbA1C}$ in predicting progression to diabetes in French men and women: data from an Epidemiological Study on the Insulin Resistance Syndrome (DESIR). Diabetes Care 2006, 29:1619-1625.

33. Selvin E, Steffes MW, Zhu H, Matsushita K, Wagenknecht L, Pankow J, Coresh J, Brancati FL: Glycated hemoglobin, diabetes, and cardiovascular risk in nondiabetic adults. N Engl J Med 2010, 362:800-811.

34. Heianza Y, Hara S, Arase Y, Saito K, Fujiwara K, Tsuji H, Kodama S, Hsieh SD, Mori Y, Shimano H, et al: HbA1c 5.7-6.4\% and impaired fasting plasma glucose for diagnosis of prediabetes and risk of progression to diabetes in Japan (TOPICS 3): a longitudinal cohort study. Lancet 2011 378:147-155.

35. Selvin E, Steffes MW, Gregg E, Brancati FL, Coresh J: Performance of A1C for the classification and prediction of diabetes. Diabetes Care 2011, 34:84-89.

doi:10.1186/1471-2458-13-1045

Cite this article as: Sun et al:: Impact of HbA1c criterion on the definition of glycemic component of the metabolic syndrome: the China health and nutrition survey 2009. BMC Public Health 2013 13:1045.

\section{Submit your next manuscript to BioMed Central and take full advantage of:}

- Convenient online submission

- Thorough peer review

- No space constraints or color figure charges

- Immediate publication on acceptance

- Inclusion in PubMed, CAS, Scopus and Google Scholar

- Research which is freely available for redistribution 